\title{
ЯЗЫК
}

\author{
А.А. Оладышкина
}

\section{ВТОРИЧНЫЕ ЭТНОНИМЫ В ВЕНСКОМ ГОРОДСКОМ ЯЗЫКЕ}

Аннотация. Анализируются этнические прозвища в венском городском языке, которые понимаются как стилистически маркированные названия этнических групп, содержащие образно-экспрессивную характеристику данного этноса, а также оценочное отношение именующего субъекта. Этноним рассматривается в широком смысле как наименование жителей не только самостоятельных государств, но и отдельных областей или местностей. Венский городской язык понимается в работе как городская языковая разновидность, представляющая собой совокупность всех употребительных в данном городе форм существования языка. Рассматриваются основные способы образования вторичных этнонимов: семантическая деривация, морфологическое словообразование и заимствование. Словообразовательный анализ вторичных этнонимов проводится на материале корпуса венских вторичных этнонимов, созданного в результате сплошной выборки из диалектных и вариантологических словарей. Определяется, что семантической основой образования вторичных этнонимов деривационным способом могут стать особенности языка или диалекта, типичные профессии, имена, ландшафты и т.д. Приводится классификация основных морфологических способов образования, а также заимствованных этнических прозвищ. Делаются выводы об этнических стереотипах жителей Вены, когда одна повторяющаяся особенность представителей этноса становится заместителем всего этнического разнообразия.

Ключевые слова: венский городской язык, этноним, этнический стереотип, городской язык, австрийский немецкий, вариантология, языковая картина мира, словообразование, семантическая деривачия, морфологическое слоообразование.

Abstract. In her article Oladyshkina analyzes Hungarian nicknames that are understood as stylistically marked names of ethnic groups containing imaginative-expressive characteristics of the given ethnos as well as attitude of the person who gives such a name. In a broad sense, ethnonyms are viewed as names used to call residents of not only independent states but also certain districts or regions. The author of the article views Hungarian Urbanolect as a kind of urban dialect that combines all forms of the language commonly used in a particular city or town. The author also analyzes the main methods of secondary ethnonym formation: semantic change, morphological derivation and borrowing. The word formation anaysis of secondary ethnonyms involves a corpus of Hungarian secondary ethnonyms created as a result of continuous sampling from dialectic and variantological dictionaries. The author discovers that peculiar features of a language or dialect, typical names for professions, landscapes, personal names, etc. can serve as the basis for formation of secondary ethnonyms through derivation. The author also offers her classification of the main morphological methods of word formation as well as borrowed ethnic nicknames. The author makes a conclusion about ethnic stereotypes of Vienna residents when one commonly encountered or observed feature of ethnos representatives substitutes the entire ethnic diversity.

Key words: word formation, language world view, Variantology, Austrian German, Urbanolect, ethnic stereotype, ethnophaulism, Viennese Urbanolect, semantic change, morphological derivation.

Л ексико-семантическая группа этнонимов представляет собой богатый исследовательский материал, открывающий доступ к языковой картине мира носителей языка и их стереотипным представлениям о различных этнических группах. В отечественной германистике проводились комплексные исследования этнонимов современного немецкого языка
(СНЯ), например, в работах Е.В. Богомягковой [1; 2]. Однако за пределами этих исследований оказался анализ этнонимов в локально маркированных формах существования СНЯ. Язык не идентичен на всей территории его распространения, особенно это касается диалектно раздробленного немецкого языкового сообщества. Так, можно предположить, что австрийская картина мира и 
стереотипные представления о других нациях принципиально отличаются от собственно немецких. И, если в литературном языке первичные этнонимы (стилистически нейтральные наименования различных народов) совпадают в австрийском и собственно немецком вариантах языка, то вторичные, стилистически окрашенные - будут отличаться. Прежде всего это актуально для южнонемецкого ареала, для которого характерна тенденция к более интенсивной регионализации и напряжённость между локально маркированными формами существования языка. Особый исследовательский интерес вызывает в данном случае городская языковая разновидность, представляющая собой совокупность всех употребительных в данном городе форм существования языка и являющаяся крупным центром языковой иррадиации [3]. Вена на протяжении веков была столицей многонационального государства. Например, в XVII в. владениями австрийских Габсбургов были королевство Чехия, Силезия, Моравия, Крайна (территория современной Хорватии и Боснии), позднее к этим территориям присоединились Венгрия, Галиция, Буковина. Вена, как важнейший экономический, промышленный и культурный центр Европы, привлекала множество переселенцев, что нашло своё отражение в городском языке. Поэтому объектом настоящего исследования стали стилистически маркированные этнонимы (или этнические прозвища) венского городского языка. Под этническими прозвищами (вторичными этнонимами) в работе понимаются стилистически маркированные названия этнических групп, содержащие образно-экспрессивную характеристику данного этноса, а также оценочное отношение именующего субъекта [2]. Этноним рассматривается в широком смысле как наименование жителей не только самостоятельных государств, но и отдельных областей или местностей.

Образование вторичных этнонимов осуществляется тремя основными способами обогащения словарного запаса: 1) семантической деривацией, 2) морфологическим словообразованием, 3) заимствованием. Ниже будет рассмотрен каждый из этих способов.

\section{1. Семантическая деривация как способ образования этнических прозвищ}

Семантическую основу вторичных этнонимов, образованных при помощи семантической деривации, составляют наименования различных этнических характеристик:

- особенности диалекта или собственного языка этноса: Heands - "Heanz", немецкоязычный жи- тель Бургенланда (обыгрывается частое употребление местного диалектного слова heanz (сейчас), звучащее отлично от венского hiez); Leachchal - "Lerche", “жаворонок” о польском еврее из-за музыкального языка;

- $\quad$ типичная профессия или ремесло: Hendlfonga "Hendlfanger", “ловец кур” о представителе цыганской диаспоры в Бургенланде; Khatsslmocha - "Katzelmacher", "производитель половников" об итальянцах;

- $\quad$ религия: Gschbritzta - "Gespritzter", "обрызганный” и Gschdramda - "Gestrammter", "приличный, строгий” о евреях;

- отдельные национальности: Breiss - "Preuße", житель Пруссии для обозначения всех жителей северной Германии;

- типичный ландшафт: Wisa - “Wieser”, “житель лугов” о жителях Бургенланда;

- типичное имя. В данном случае речь идёт о процессе апеллятивизации, т.е. перехода имен собственных в разряд имён нарицательных: Wasdl, Waschdl - диалектная краткая форма имени Sebastian для обозначения тирольца; Wentssl - Wenzel для обозначения чехов; Jantschi - Hans для обозначения венгров; Marianka - Marjanka для обозначения чешки; Bifke - Piefke, восточно-немецкая фамилия, предположительно, фамилия немецкого военного композитора.

\section{2. Морфологический способ образования этнических прозвищ}

Большая группа этнических прозвищ является результатом активных словообразовательных процессов немецкого языка. Основными способами образования производных этнических прозвищ являются аффиксация, усечение слова и словосложение.

- Аффиксальный способ представлен как процессами префиксации, так и суффиксации. Важной особенностью является участие пейоративных аффиксов, которые, присоединяясь к первичному этнониму, образуют стилистически маркированное этническое прозвище.

- при помощи пейоративных суффиксов: этноним + -ak (Bemak - "Böhme", чех); этноним + -aka (Itaka - "Itaker", итальянец); продукт питания + -inga (Mameladinga - "Marmeladinger", немец);

- при помощи нейтральных суффиксов: этноним + -eser (Japanesa - "Japaneser", японец);

- при помощи пейоративных полупрефиксов Grudsi- ("Kruzi"): Grudsidiakn - "Kruzitürken", турки; при помощи нейтральных полусуффиксов: типичный товар + -man (Essimon - "Essigmann", 
"уксусник” об итальянцах; Figuariman "Figurenmann", "человек с фигурками" об итальянцах); продукт питания + bruada (Mameladbruada - "Marmeladebruder", "мармеладник” о немцах);

- при помощи пейоративных полусуффиксов: топоним + -schedel (Mosdschedel - "Mostschädel", житель региона Мостфиртель, житель Верхней Австрии).

- Усечение этнонимов: Japs - усечённая форма от Japaner (японец).

- Словосложение. Типичными компонентами при данном способе словообразования являются первичный этноним и переосмысленный уточняющий компонент, выражающий стереотипное представление носителя венского урбанолекта:

- типичный товар + этноним: Dsifegrowod "Zwiebelkroate", “луковый” хорват из-за развитого сельского хозяйства и импорта овощей в Вену; Golefgrowod - "Kochlöffelkroate", хорват-“торговец половниками”; Khimmediak - “Kümmeltürke", “тминный” турок; Fedarjud "Federnjud”, еврей-“торговец перьями”;

- типичная профессия + этноним: Dsiaglbem "Ziegelböhme", чех-“каменщик”; Gleisbem "Gleisböhme", "рельсовый” чех;

- типичный внешний признак + этноним: Binkljud - "Bündeljude", еврей-“торговец с тюками";

- типичный товар + вторичный этноним: Buariwentssl - "Porreewenzel", сочетание слов "лук-порей” и типичного словацкого имени Wenzel для обозначения словака, при этом семантическая деривация затрагивает обе части этого слова.

\section{3. Заимствование как способ образования этнических прозвищ}

Заимствованные этнические прозвища можно разделить на две группы:

- слова, сохраняющие в языке-реципиенте то же значение, что и в языке-источнике: babuschka (от словацкого babuška - старая женщина) старая женщина из Чехии; Goj (иврит Goj) - христианин, не еврей.

- заимствованные слова, подвергающиеся семантической деривации и не употребляемые в исходном значении. Например, Dsopak - чешское заимствование copak - “человек с косой”, таким образом, семантической основой вторичного этнонима Dsopak (словак) становится наименование особенности внешности. Khanak (от полинезийского или гавайского Kannaka -
Mensch) - переосмыслено как любой мигрант из южной страны, а в Вене употребляется в значении “турок”. Tschusch (от югославского čuješ? Verstehst du?) - переосмыслено как общее обозначение рабочих мигрантов с юга Европы, прежде всего с Балканского полуострова.

Особую роль во всех трёх процессах формирования способах образования вторичных этнонимов играет семантическая деривация, поскольку она особенно ярко показывает этностереотипы носителей венского городского языка о представителях других наций. Под этностереотипами здесь понимаются схематический образ этноса, выражающий привычное отношение говорящего и сложившийся под влиянием социальных условий и предшествующего опыта [4]. Как правило, одна, самая часто встречающаяся этническая характеристика замещает все представления о народе, сводя всё разнообразие к типичной профессии, имени или религии. Данные процессы коррелируют с образованием вторичных значения у первичных этнонимов, когда наименование этноса получает переносное значение и дополнительно обозначает типичную черту характера или типичный продукт питания, например: Russ "Russe" - 1. русский; 2. (переносное значение) примитивный, грубый человек [5].

Таким образом, анализ вторичных этнонимов венского городского языка позволяет пополнить представление о языковой картине мира жителя австрийской столицы. Этническими прозвищами наделяют народы, представители которых активны в городском пространстве Вены. Это, прежде всего, чехи, евреи, немцы, итальянцы, турки, хорваты и словаки - говоря точнее, граждане бывшей многонациональной австрийской империи, а в современном мире - жители пограничных государств. Анализ этнических прозвищ позволяет сделать выводы о стереотипах жителей Вены. Одна из ярких и повторяющихся особенностей представителей некоторой нации становится заместителем всего этнического разнообразия, так, например, все представители какого-либо народа переосмысливаются как люди определённой профессии. Эти стереотипы позволяют сделать выводы о исторически сложившихся отношениях в городском пространстве. Вторая многочисленная группа этнонимов - наименования жителей различных областей (федеральных земель) Австрии. Этнические прозвища иллюстрируют сложившееся противостояние жителей столицы и провинции. Интересным направлением дальнейших исследований представляется анализ фразеологизмов венского городского языка с компонентомэтнонимом. 


\section{Филология: научные исследования 4(24) • 2016}

\section{Список литературы:}

1. Богомягкова Е.В. Морфологические способы образования этнических прозвищ // Иностранные языки в контексте культуры: Межвузовский сборник статей по материалам конференций. Пермь: ФГБОУ ВПО «Пермский гос. нац. исследовательский ун-т», 2012. С. 19-23.

2. Богомягкова Е.В. Этнонимы современного немецкого языка: Автореф. дисс. ... канд. филол. наук. СПб., 2005.19 с.

3. Копчук Л.Б. Развитие обиходно-разговорного языка в немецкоязычных странах в свете в социолингвистической концепции языковой эволюции // Вестник Балтийского федерального университета им. И. Канта. 2014. Вып. 2. С. 51-61.

4. Кочнова К.А. Роль этнических стереотипов в межкультурной коммуникации [Электронный ресурс] // Вестник Мининского университета. 2013. Вып. 2. URL: http://vestnik.mininuniver.ru/upload/iblock/abf/7-rol-etnicheskikhstereotipov-v-mezhkulturnoy-kommunikatsii.pdf (дата обращения: 10.04.2016).

5. Оладышкина А.А. Семантическая структура этнонимов и отэтнонимических апеллятивов в венском городском языке // Теоретические и практические аспекты лингвистики, литературоведения, методики преподавания иностранных языков. Н. Новгород: Мининский университет, 2015. С. 62-66.

6. Hornung M., Grüner S. Wörterbuch der Wiener Mundart. Wien: ÖBV und HPT VerlagsgmbH, $2002.806 \mathrm{~s}$.

7. Wehle P. Sprechen Sie Wienerisch? Von Adaxl bis Zwutschkerl. Wien: Überreuter, 2012. $312 \mathrm{~s}$.

\section{References (transliterated):}

1. Bogomyagkova E.V. Morfologicheskie sposoby obrazovaniya etnicheskikh prozvishch // Inostrannye yazyki v kontekste kul'tury. Mezhvuzovskii sbornik statei po materialam konferentsii. Perm': FGBOU VPO «Permskii gos. nats. issledovatel'skii un-t», 2012. S. 19-23.

2. Bogomyagkova E.V. Etnonimy sovremennogo nemetskogo yazyka: Avtoref. diss. ... kand. filol. nauk. SPb., 2005.19 s.

3. Kopchuk L.B. Razvitie obikhodno-razgovornogo yazyka v nemetskoyazychnykh stranakh v svete v sotsiolingvisticheskoi kontseptsii yazykovoi evolyutsii // Vestnik Baltiiskogo federal'nogo universiteta im. I. Kanta. 2014. Vyp. 2. S. 51-61.

4. Kochnova K.A. Rol' etnicheskikh stereotipov v mezhkul'turnoi kommunikatsii [Elektronnyi resurs] // Vestnik Mininskogo universiteta. 2013. Vyp. 2. URL: http://vestnik.mininuniver.ru/upload/iblock/abf/7-rol-etnicheskikh-stereotipov-vmezhkulturnoy-kommunikatsii.pdf, svobodnyi (data obrashcheniya: 10.04.2016).

5. Oladyshkina A.A. Semanticheskaya struktura etnonimov i otetnonimicheskikh apellyativov v venskom gorodskom yazyke // Teoreticheskie i prakticheskie aspekty lingvistiki, literaturovedeniya, metodiki prepodavaniya inostrannykh yazykov. N. Novgorod: Mininskii universitet, 2015. S. 62-66.

6. Hornung M., Grüner S. Wörterbuch der Wiener Mundart. Wien: ÖBV und HPT VerlagsgmbH, 2002. $806 \mathrm{~s}$.

7. Wehle P. Sprechen Sie Wienerisch? Von Adaxl bis Zwutschkerl. Wien: Überreuter, 2012. 312 s. 